\title{
Trifluoromethyl Boron Dipyrromethene Derivatives as Potential Photosensitizers for Photodynamic Therapy
}

\author{
Jian-Yong Liu * (1), Peng-Zhen Zhou, Jia-Lin Ma and Xiao Jia \\ State Key Laboratory of Photocatalysis on Energy and Environment \& National \& Local Joint Biomedical \\ Engineering Research Center on Photodynamic Technologies, College of Chemistry, Fuzhou University, \\ Fuzhou 350108, China; 18714968018@163.com (P.-Z.Z.); MWY4512938@163.com (J.-L.M.); \\ jiaxiao@fzu.edu.cn (X.J.) \\ * Correspondence: liujianyong82@163.com; Tel.: +86-591-22867105
}

Received: 17 January 2018; Accepted: 15 February 2018; Published: 19 February 2018

\begin{abstract}
In this study, two novel boron dipyrromethene-based photosensitizers (BDP3 and BDP6) substituted with three or six trifluoromethyl groups have been synthesized and characterized with various spectroscopic methods, and their photo-physical, photo-chemical, and photo-biological properties have also been explored. The two photosensitizers are highly soluble and remain nonaggregated in $\mathrm{N}, \mathrm{N}$-dimethylformamide as shown by the intense and sharp Q-band absorption. Under red light irradiation $\left(\lambda=660 \mathrm{~nm}, 1.5 \mathrm{~J} / \mathrm{cm}^{2}\right)$, both photosensitizers show high and comparable cytotoxicity towards HepG2 human hepatocarcinoma and HeLa human cervical carcinoma cells with $\mathrm{IC}_{50}$ values of $0.42-0.49 \mu \mathrm{M}$. The high photocytotoxicity of BDP3 and BDP6 can be due to their high cellular uptake and low aggregation tendency in biological media, which result in a high efficiency to generate reactive oxygen species inside the cells. Confocal laser fluorescence microscopic studies indicate that they have superior selective affinities to the mitochondria and lysosomes of HepG2 and HeLa cells. The results show that these two trifluoromethyl boron dipyrromethene derivatives are potential anticancer agents for photodynamic therapy.
\end{abstract}

Keywords: photosensitizer; BODIPY; photodynamic therapy; reactive oxygen species

\section{Introduction}

Photodynamic therapy (PDT) is a clinically approved and non-invasive therapeutic procedure and has been entering the mainstream of cancer treatments [1-6]. PDT requires a photosensitizer (PS), light, and oxygen to initiate photo-chemical reactions that may result in the primary tumor destruction and provide protection against metastasis via the local generation of reactive oxygen species (ROS) [7-9]. An ideal photosensitizer with a high therapeutic efficacy should have the following suitable physicochemical properties: intense absorption in the phototherapeutic window (630-850 nm) [10], stable chemical structure and simple synthetic route, high ROS quantum yield, low dark toxicity and skin phototoxicity, easy clearance from the body, high selectivity to tumor cells, reasonable fluoro-/chemi-luminescence for effective tumor diagnostics, and favorable solubility in body's fluids and injectable solvents [11-13]. In addition, the pharmacokinetics is also important for a new photosensitizer. The ideal photosensitizer should stably retain in the circulation for a sufficient time so that it can either localize in malignant tissues and/or their vasculature. Nowadays, the photosensitizers used in clinical practice are mainly tetrapyrrole macrocycles such as porphyrin $[1,14]$, chlorin [15], and phthalocyanine [16,17]. However, the drawbacks of this class of molecules are the cumbersome synthesis and purification processes $[18,19]$.

As versatile fluorescent dyes, boron dipyrromethenes (BODIPYs) are characterized by strong absorption in the visible and near-infrared region $[9,20]$, high photo-stability, low sensitivity to 
environmental variation, and the easily modified basic core with tunable optical properties [21]. Heavy atoms (I [22,23], Br [24,25], Pt [26]) are incorporated into the BODIPY core to facilitate intersystem crossing, which can enhance the generation efficiency of singlet oxygen, and obtain a new candidate for photodynamic sensitizers [27-29]. Drug candidates with one or more fluorine atoms have become commonplace $[10,30]$. The incorporation of fluorine or trifluoromethyl groups into a drug allows the simultaneous modulation of electronic, lipophilic, and steric parameters. The lipophilicity of fluorine can enhance the cell membrane permeability so as to improve the bioavailability of drug candidates [31]. The strong electronegativity of fluorine can increase the binding force between the ligand and target, and optimize the pharmacodynamic properties of drugs. In addition, the stable C-F bond contributes to the metabolic stability of the drugs in body, therefore improving the pharmacokinetic properties of drugs [32,33]. However, incorporating fluorine or trifluoromethyl groups into the BODIPY core with a view to improving their therapeutic outcome has been seldom reported [34]. Herein, we demonstrate two novel BODIPY derivatives bearing 3 and 6 trifluoromethyl groups and named them BDP3 and BDP6, respectively. Their photo-physical, photo-chemical, and photo-biological properties have also been explored. BDP3 and BDP6 show slight aggregation in the Roswell Park Memorial Institute (RPMI) 1640 cell culture medium, mainly exist in monomer form. Methyl thiazolyl tetrazolium (MTT) assays show that the two photosensitizers have the high photocytotoxicity against HepG2 and HeLa cancer cells with $\mathrm{IC}_{50}$ values of $0.42-0.49 \mu \mathrm{M}$. Subcellular localization experiments show that the two compounds are not found in the nucleus, but largely distribute in the mitochondria and lysosomes of HepG2 and HeLa cells. The two compounds with a different number of trifluoromethyl groups show almost the same photocytotoxicity. However, when we evaluate the performance of a new drug, cytotoxicity is not the only index. Its pharmacokinetics is also very important. BDP6 containing more trifluoromethyl groups does not show a higher photocytotoxicity than BDP3. Maybe it has better pharmacokinetic characteristics. In the future, we will further explore the pharmacokinetic properties of the two BODIPY derivatives as suitable photosensitizers.

\section{Results and Discussion}

\subsection{Molecular Design and Synthesis}

The syntheses of BODIPY derivatives BDP3 and BDP6 were accomplished by a multi-step synthetic procedure as shown in Scheme 1. The BODIPY mother compound $\mathbf{1 a}$ or $\mathbf{1} \mathbf{b}$ was first prepared by treating 2,4-dimethylpyrrole with 4-trifluoromethylbenzaldehyde or 3,5-bis(trifluoromethyl)benzaldehyde via sequential condensation, oxidation, and complexation reactions according to a classic procedure [21]. Both $\mathbf{1 a}$ and $\mathbf{1 b}$ were then treated with $\mathrm{I}_{2}$ and $\mathrm{HIO}_{4}$ in absolute ethanol to afford iodo-BODIPY $\mathbf{2 a}$ and $\mathbf{2 b}$, respectively. Iodine atom is incorporated into the 2 or 6 position of the BODIPY mother core, which can facilitate intersystem crossing, therefore promoting the generation of singlet oxygen. Finally, compound $\mathbf{2 a}$ or $\mathbf{2 b}$ underwent a condensation reaction with 4-trifluoromethylbenzaldehyde or 3,5-bis(trifluoromethyl)benzaldehyde in the presence of piperidine and glacial acetic acid in toluene to give BDP3 or BDP6 in a moderate yield. Both compounds have a larger $\pi$-conjugated structure than their mother BODIPYs, showing strong absorbances in the red visible region, which is a desirable characteristic for efficient photosensitizers. All these new compounds were characterized by various spectroscopic methods. 


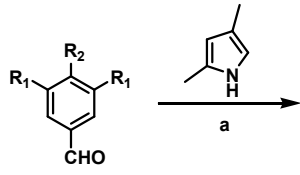

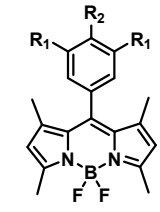

$\underset{1 \mathrm{~b} \mathrm{R}_{1}=\mathrm{CH}, \mathrm{R}_{3}=\mathrm{CF}_{3}=\mathrm{H}}{\mathrm{R}_{3}}$

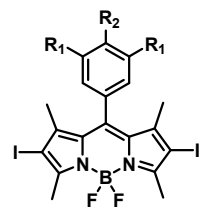

2a $\mathrm{R}_{1}=\mathrm{H}, \mathrm{R}_{2}=\mathrm{CF}_{3}$
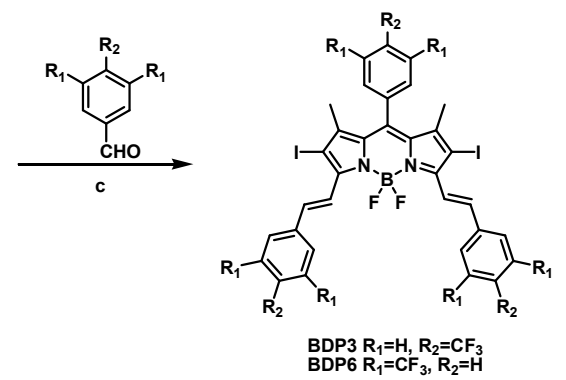

Scheme 1. Synthetic route of BDP3 and BDP6. a: (1) TFA, $\mathrm{CH}_{2} \mathrm{Cl}_{2}$ (2) 2,3-dichloro-5,6-dicyano- $p$ benzoquinone (3) $\mathrm{Et}_{3} \mathrm{~N}, \mathrm{BF}_{3} \cdot \mathrm{Et}_{2} \mathrm{O}$. b: $\mathrm{I}_{2}, \mathrm{HIO}_{4}$. c: piperidine, acetic acid, $\mathrm{Mg}\left(\mathrm{ClO}_{4}\right)_{2}$.

\subsection{Photo-Physical and Photo-Chemical Properties}

The electronic absorption as well as basic photo-physical and photo-chemical properties of these two trifluoromethyl BODIPY derivatives BDP3 and BDP6 was investigated in N,Ndimethylformamide (DMF) and the data are summarized in Table 1. As shown in Figure 1, both compounds give typical absorption spectra of non-aggregated BODIPY, showing an intense and sharp Q-band at 638 (or 640) nm, which strictly follows the Lambert-Beer's law. Upon excitation at $610 \mathrm{~nm}$, BDP3 and BDP6 show a narrow fluorescence emission at 662 and $661 \mathrm{~nm}$, respectively. The fluorescence quantum yields $\left(\Phi_{\mathrm{F}}\right)$ were determined to be 017 and 0.16 by using unsubstituted zinc(II) phthalocyanine ( $\mathrm{ZnPc})\left(\Phi_{\mathrm{F}}=0.28\right)$ as the standard compound (Table 1) [18]. To evaluate the photosensitizing potential, the singlet oxygen quantum yields $\left(\Phi_{\Delta}\right)$ of these two BODIPY derivatives were also determined in DMF by a steady-state method using 1,3-diphenylisobenzofuran (DPBF) as the singlet oxygen scavenger and $\mathrm{ZnPc}$ as the standard. The concentration of the quencher was monitored spectroscopically at $415 \mathrm{~nm}$ along with time, from which the values of $\Phi_{\Delta}$ could be determined by the method described previously [19]. The data are also summarized in Table 1. Figure 2 compares the rates of decay of DPBF using the two BODIPYs and ZnPc as the photosensitizers. It can be seen that the two trifluoromethyl BODIPY derivatives are efficient singlet oxygen generators $\left(\Phi_{\Delta}=0.36\right.$ and 0.32$)$ (Table 1). These results show that BDP3 and BDP6 have similar electronic absorption, fluorescence emission and singlet oxygen generation efficiency.

Table 1. Photo-physical/photo-chemical data of BDP3 and BDP6 in DMF.

\begin{tabular}{ccccc}
\hline Compounds & $\lambda_{\max } / \mathbf{n m}(\log \varepsilon)$ & $\lambda_{\text {em }} / \mathbf{n m}^{\mathbf{a}}$ & $\boldsymbol{\Phi}_{\mathrm{F}}{ }^{\mathbf{b}}$ & $\boldsymbol{\Phi}_{\Delta}{ }^{\mathrm{c}}$ \\
\hline BDP3 & $638(4.84)$ & 662 & 0.17 & 0.36 \\
BDP6 & $640(5.29)$ & 661 & 0.16 & 0.32 \\
\hline
\end{tabular}

a Excited at $610 \mathrm{~nm} .{ }^{\mathrm{b}, \mathrm{c}}$ Using unsubstituted zinc(II) phthalocyanine $(\mathrm{ZnPc})$ in DMF as the standard $\left(\Phi_{\mathrm{F}}=0.28\right.$, $\left.\Phi_{\Delta}=0.56\right) ; \Phi_{\mathrm{F}}$ is the fluorescence quantum yield; $\Phi_{\Delta}$ is the singlet oxygen quantum yield.
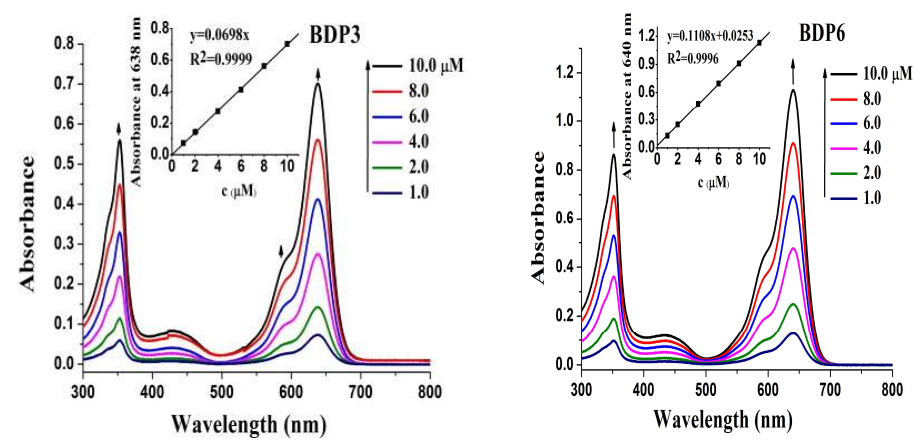

Figure 1. Electronic absorption spectra of BDP3 and BDP6 at various concentrations in DMF. The inset shows the variation of the Q-band absorbance with the concentration of BODIPYs. 


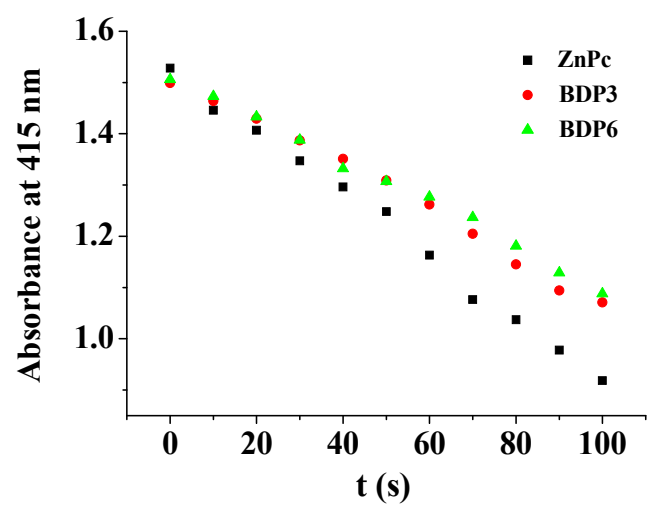

Figure 2. Comparison of the degradation rates of 1,3-diphenylisobenzofuran (DPBF) in DMF as monitored spectroscopically at $415 \mathrm{~nm}$, using BDP3 and BDP6 as the photosensitizers and unsubstituted zinc(II) phthalocyanine ( $\mathrm{ZnPc}$ ) as the standard.

\subsection{In Vitro Studies}

\subsubsection{Photocytotoxicity Studies}

BODIPY derivatives usually have a low solubility and tend to aggregate in biological media. Cremophor EL is a well-known surfactant, it was often used to promote the dissolution of hydrophobic photosensitizers and reduce their aggregation behavior in biological media [35]. Similarly, in this report, Cremophor EL was added to enhance the solubility and dispersion of BODIPYs in biological media. The in vitro photodynamic activities of photosensitizers BDP3 and BDP6 in Cremophor EL emulsions were investigated against two different cell lines (HepG2 and HeLa cancer cells). The assay of methyl thiazolyl tetrazolium (MTT, Gen View Co., Ltd., Tallahassee, FL, USA) was employed to determine the cytotoxicity of BDP3 and BDP6 (Figure 3, Supplement Tables S1-S4). As shown in the dose-dependent survival curves (Figure 3), both compounds have the essentially negligible cytotoxicity in the absence of light up to $2 \mu \mathrm{M}$, but exhibit a high phototoxicity to photosensitizer-stained HepG2 or HeLa cells upon irradiation with the light dosage of $1.5 \mathrm{~J} / \mathrm{cm}^{2}(\lambda=660 \mathrm{~nm})$. The corresponding $\mathrm{IC}_{50}$ values, defined as the dye concentrations required to kill $50 \%$ of the cells, are summarized in Table 2. For HepG2 cells, the $\mathrm{IC}_{50}$ values of BDP3 and BDP6 were $0.49 \mu \mathrm{M}$ and $0.45 \mu \mathrm{M}$, respectively. For HeLa cells, the $\mathrm{IC}_{50}$ values of these two compounds were $0.42 \mu \mathrm{M}$ and $0.45 \mu \mathrm{M}$. Their in vitro photocytotoxicity exceeds the level attained by Foscan, a clinically used photosensitizing drug $\left(\mathrm{IC}_{50}=0.8 \mu \mathrm{M}\right.$ at a light dosage of $1.8 \mathrm{~J} / \mathrm{cm}^{2}$ ) [36]. The two BODIPYs have superior photodynamic activities and similar highly potency and effects on HepG2 and HeLa cells, indicating that the two BODIPYs may be used as photosensitizer agents for treating a wide range of cancers.

With the large $\pi$-conjugated structure, BODIPY derivatives always tend to aggregate in the aqueous solution, as a result, their photocytotoxicities are significantly reduced or even disappeared [23]. To account for the in vitro photodynamic activities, the aggregation behavior of photosensitizers BDP3 and BDP6, formulated with Cremophor EL in the RPMI 1640 culture medium, was examined by the electronic absorption and fluorescence spectroscopic methods (Figure 4). It can been seen that the Q-bands of all these compounds remain sharp and intense, meanwhile strong fluorescence emission peaks are observed at ca. $662 \mathrm{~nm}$ upon excitation at $610 \mathrm{~nm}$ indicating the two BODIPYs are not significantly aggregated under these conditions, which seems to accord with their high photodynamic activities. 
Table 2. $\mathrm{IC}_{50}$ values of BDP3 and BDP6 against HepG2 and HeLa cells.

\begin{tabular}{|c|c|c|}
\hline \multirow{2}{*}{ Compounds } & HepG2 & HeLa \\
\hline & \multicolumn{2}{|c|}{$\mathrm{IC}_{50}(\mu \mathrm{M})^{\mathrm{a}}$} \\
\hline BDP3 & 0.49 & 0.42 \\
\hline BDP6 & 0.45 & 0.45 \\
\hline
\end{tabular}

${ }^{\text {a }}$ Defined as the photosensitizer concentration required to kill $50 \%$ of the cells.

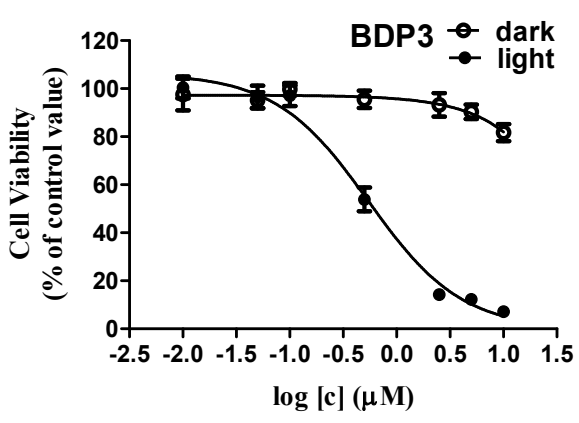

a

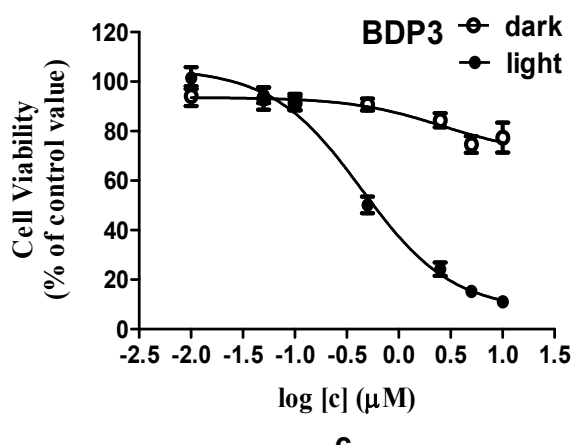

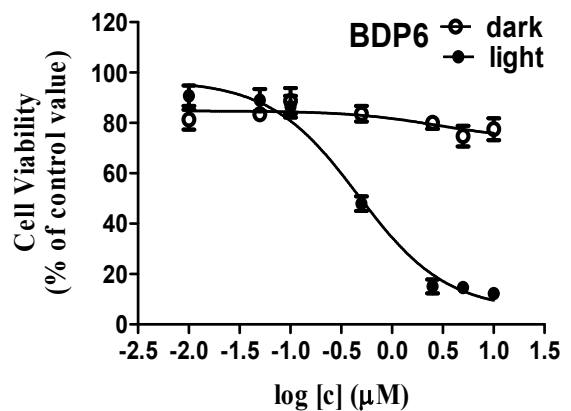

b

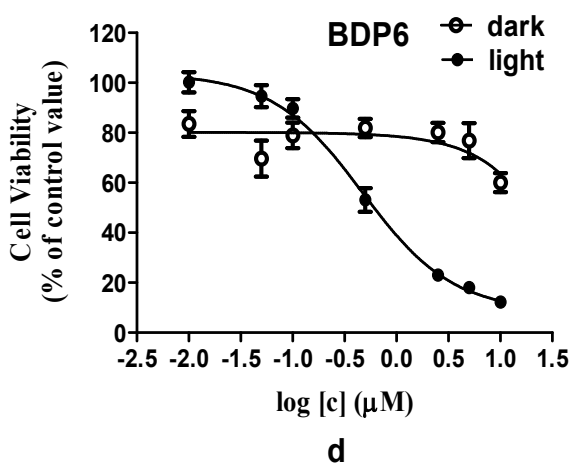

Figure 3. Effects of BDP3 and BDP6 on HepG2 $(\mathbf{a}, \mathbf{b})$ and HeLa $(\mathbf{c}, \mathbf{d})$ cells in dark $(\bigcirc)$ and in light $(\bullet$ $\left(\lambda=660 \mathrm{~nm}, 1.5 \mathrm{~J} / \mathrm{cm}^{2}\right)$. Data are expressed as Mean \pm SEM of three independent experiments; six replicates were used for each concentration in each experiment.
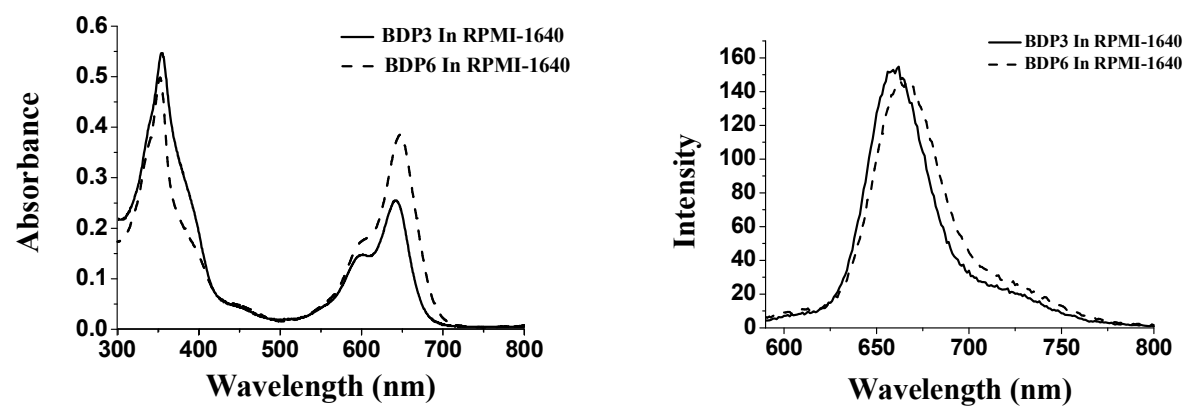

Figure 4. Electronic absorption (left) and Fluorescence emission spectra (right) of BDP3 and BDP6, formulated with Cremophor EL $(0.05 \%)$ in the RPMI 1640 culture medium (all at $10 \mu \mathrm{M})$.

\subsubsection{Measurements of Intracellular ROS}

The irradiation of the photosensitizers leads to the production of ROS, which is thought to be the main mediator of cellular death induced by PDT and plays an important role in apoptosis [7]. ROS can mediate cellular effects such as lipid peroxidation and vascular effects, thus resulting in direct or 
indirect cytotoxicity effects on the treated cells. Here, the intracellular ROS generation efficiency of both BODIPYs against HepG2 cells was also examined with $2^{\prime}, 7^{\prime}$-dichlorodihydrofluorescein diacetate (DCFH-DA) as the indicator [37]. As previously reported, DCFH-DA is non-fluorescent and its oxidized product $2^{\prime}, 7^{\prime}$-dichlorofluorescein (DCF) by ROS can emit green fluorescence. The treatment of DCFH-DA with BDP3, BDP6 and Rosup (positive control) induced a strong fluorescence (Figure 5, Table 3). These findings suggest that the two BODIPYs have the high ROS generation ability and show no obvious difference. The results are consistent with the MTT assay results. As a negative control, the culture medium without agent has no effect on the ROS levels.

Table 3. Intracellular $2^{\prime}, 7^{\prime}$-dichlorofluorescein (DCF) fluorescence of HepG2 cells after incubation with BDP3 $(0.5 \mu \mathrm{M})$, BDP6 $(0.5 \mu \mathrm{M})$ for $24 \mathrm{~h}$ at $37^{\circ} \mathrm{C}$.

\begin{tabular}{|c|c|c|c|}
\hline Compounds & Rosup & BDP3 & BDP6 \\
\hline Fluorescence Intensity of DCF & $4967.72 \pm 154.29$ & $4658.25 \pm 60.60$ & $4465.25 \pm 164.95$ \\
\hline
\end{tabular}

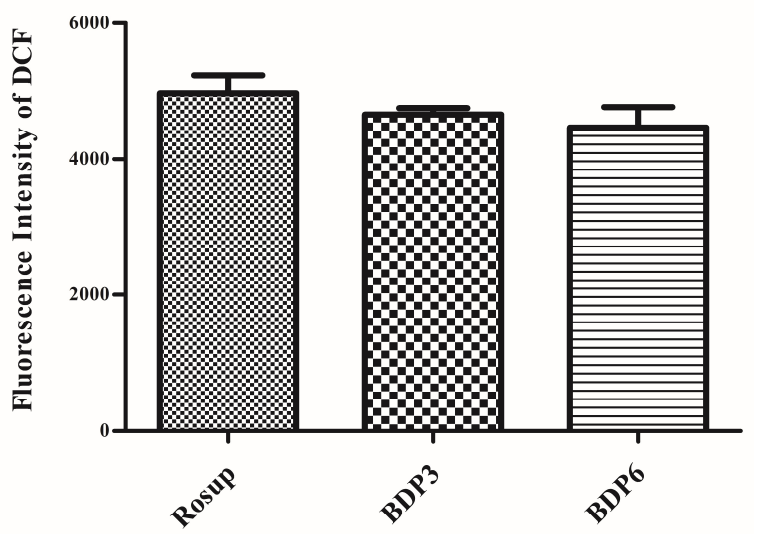

Figure 5. Intracellular $2^{\prime}, 7^{\prime}$-dichlorofluorescein (DCF) fluorescence of HepG2 cells after incubation with BDP3 $(0.5 \mu \mathrm{M})$, BDP6 $(0.5 \mu \mathrm{M})$ for $24 \mathrm{~h}$ at $37^{\circ} \mathrm{C}$, and then under light irradiation for 20 min with a LED lamp of light dosage of $1.5 \mathrm{~J} / \mathrm{cm}^{2}(\lambda=660 \mathrm{~nm})$. The culture media with Rosup $(50 \mu \mathrm{g} / \mathrm{mL})$ were set as the positive controls. Values are Mean \pm SEM of three independent experiments; six replicates were used for each experiment.

\subsubsection{Subcellular Localization}

Cellular uptake and subcellular localization of BDP3 and BDP6 in the HepG2 and HeLa cells were also carried out by an Olympus FV1000 Confocal Laser Scanning Microscope (Olympus Instrument Co., Ltd., Shinjuku-ku, Tokyo, Japan). The cells were first incubated with BDP3 or BDP6 in the culture medium for $24 \mathrm{~h}$ and then stained with 4,6-diamidino-2-phenylindole (DAPI) (incubated for $10 \mathrm{~min}$ ), Mito-Tracker Green (incubated for $30 \mathrm{~min}$ ) or Lyso-Tracker DND-26 (incubated for $1 \mathrm{~h}$ ), which were respectively specific dyes for nucleus, lysosomes, and mitochondria. After incubation with these two compounds for $24 \mathrm{~h}$ and upon excitation at $633 \mathrm{~nm}$, the HepG2 and HeLa cells showed high intracellular fluorescence (Figure 6 and Figure S1), indicating that there was a substantial uptake of the photosensitizers. As shown in Figure 6c,e, against HepG2 cells, both the fluorescence caused by the Mito-Tracker Green (excited at $488 \mathrm{~nm}$, monitored at 510-570 nm) or Lyso-Tracker DND-26 (excited at $488 \mathrm{~nm}$, monitored at 510-570 nm) can superimpose on the fluorescence caused by photosensitizers BDP3 and BDP6 (excited at $633 \mathrm{~nm}$, monitored at 650-750 nm). Furthermore, the similar fluorescence intensity profiles (Figure $6 \mathrm{~d}, \mathrm{f}$ ) traced along the red line also confirm that these two BODIPYs can target mitochondria and lysosomes of cells well. The fluorescence images of BDP3 or BDP6 cannot 
superimpose on that of DAPI (excited at $405 \mathrm{~nm}$, monitored at 425-475 nm) (Figure 6a,b), indicating that both BODIPYs are not localized in the nucleus. The same results were observed in the HeLa cells

(Figure S1).

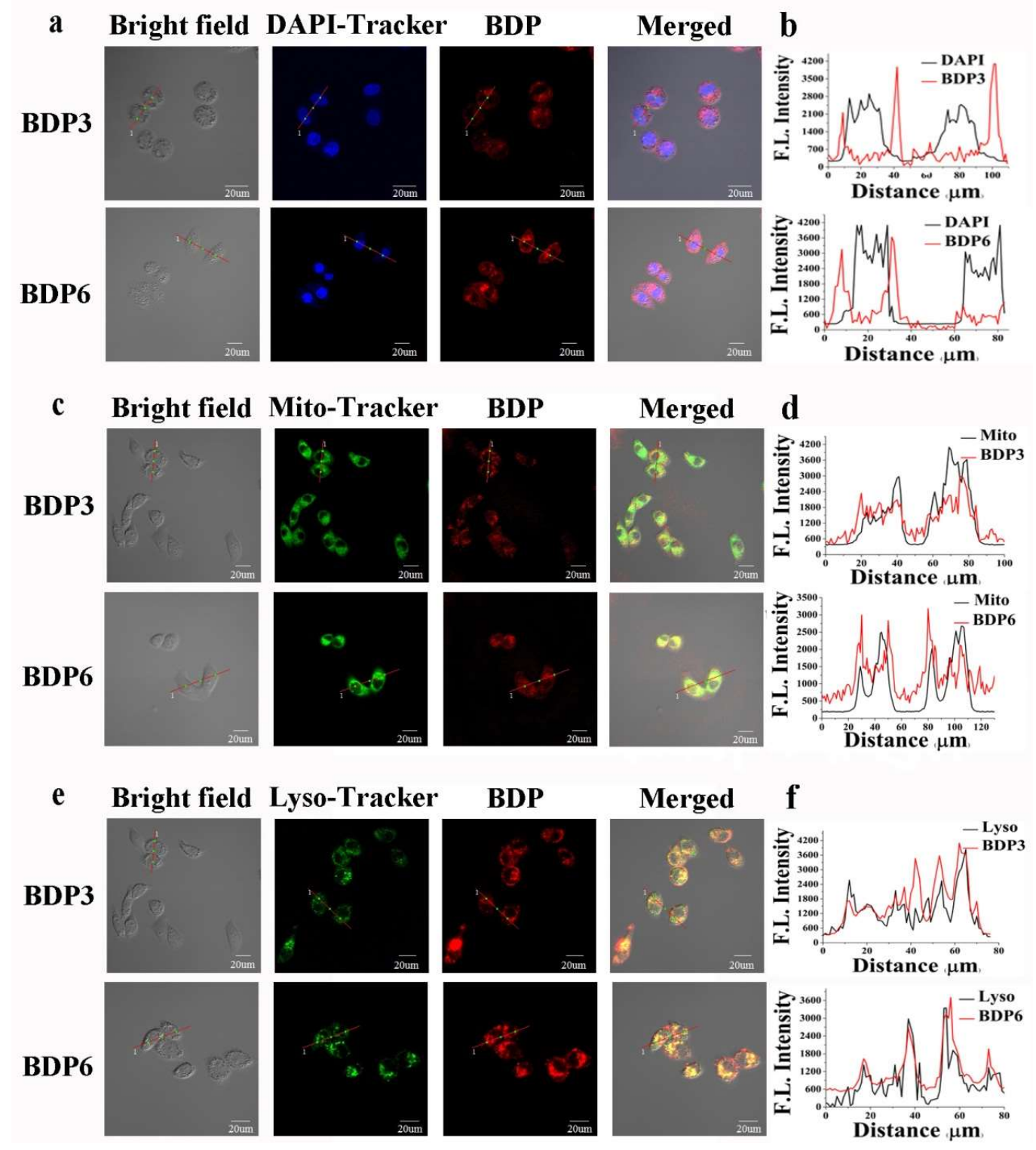

Figure 6. Visualization of the intracellular fluorescence of HepG2 cells for DAPI (in blue, a), Mito-Tracker Green (in green, c), Lyso-Tracker (in green, e), and BDP3 or BDP6 (in red, $2 \mu \mathrm{M}$ ). Fluorescence intensity profiles of DAPI (b), Mito-Tracker Green (d), Lyso-Tracker (f), and BDP3 or BDP6 (2 $\mu \mathrm{M})$ traced along the red line in $(\mathbf{a}, \mathbf{c}, \mathbf{e})$.

\section{Materials and Instruments}

Dichloromethane and toluene were distilled from calcium hydride and sodium, respectively. Chromatographic purifications were performed on silica gel (Qingdao Ocean, Qingdao, Shandong, China, 200-300 mesh) columns with the indicated eluents. RPMI 1640 cell culture medium (Gibco, Grand Island, NY, USA) was purchased from Ding Biotechnology Co., Ltd., Haimen, China. HepG2 human hepatocarcinoma and HeLa human cervical carcinoma cells were obtained from the cell bank of Shanghai Institutes for Biological Sciences. The methyl thiazolyl tetrazolium (MTT, Gen View Co., Ltd., Tallahassee, FL, USA) assay was performed on a 96-well sterile cell culture plate (NEST Biotechnology 
Co., Ltd., Wuxi, Jiangsu, China). All other solvents and reagents were of analytical grade and used as received.

${ }^{1} \mathrm{H}-\mathrm{NMR}$ spectra were recorded on AVANE III $400\left({ }^{1} \mathrm{H}, 400 \mathrm{MHz}\right)$ instrument (Bruker, Karlstuhe, Germany) in $\mathrm{CDCl}_{3}$. Chemical shifts were expressed in ppm relative to TMS (0 ppm). High-resolution mass spectra (HRMS) analysis was carried out on an Agilent 6520 ACURATE-Mass Q-TOF Mass Spectrometer (Agilent Technologies, Santa Clara, CA, USA). Electronic absorption spectra were measured on a Beijing Puxi Tu-1901 Spectrometer (Beijing PuXi Spectrum Optical Instrument Co., Ltd., Beijing, China) and fluorescence spectra were obtained on a VARIAN Carye Elipse Fluorescence spectrometer (Agilent Technologies, Santa Clara, CA, USA). Subcellular localization was carried out on an Olympus FV1000 Confocal Laser Scanning Microscope (Olympus Instrument Co., Ltd., Shinjuku-ku, and Tokyo, Japan)

\subsection{Synthesis}

\subsubsection{Synthesis of $\mathbf{1 a}$}

To the solution of 4-trifluoromethylbenzaldehyde $(1.50 \mathrm{~g}$, $9.30 \mathrm{mmol})$ and 2,4-dimethylpyrrole $(1.82 \mathrm{~g}, 19.08 \mathrm{mmol})$ in anhydrous dichloromethane $(80 \mathrm{~mL})$ was added one drop of trifluoroacetic acid. The mixture was stirred overnight at ambient temperature and then the solution of 2,3-dichloro-5,6dicyano-p-benzoquinone $(2.12 \mathrm{~g}, 9.35 \mathrm{mmol})$ in anhydrous dichloromethane $(150 \mathrm{~mL})$ was added. The resulting mixture was stirred continuously for another $4 \mathrm{~h}$. After the addition of triethylamine $(18 \mathrm{~mL}, 0.13 \mathrm{~mol}), \mathrm{BF}_{3} \cdot \mathrm{Et}_{2} \mathrm{O}(18 \mathrm{~mL}, 0.15 \mathrm{~mol})$ was dropwise added into the mixture, which was cooled in an ice-water bath. The mixture was stirred overnight at ambient temperature and then filtered through a celite pad to remove black solid impurities. The filtrate was then washed with saturated $\mathrm{NaHCO}_{3}$ aqueous solution $(200 \mathrm{~mL} \times 2)$, followed by saturated $\mathrm{NaCl}$ aqueous solution $(200 \mathrm{~mL} \times 2)$. The organic fraction was dried over anhydrous $\mathrm{Na}_{2} \mathrm{SO}_{4}$ and then concentrated to dryness under vacuum. The crude product was purified by silica gel column chromatography using $\mathrm{CH}_{2} \mathrm{Cl}_{2}$ /petroleum ether $(1: 2, v / v)$ as the eluent to give $1 \mathrm{a}$ as the orange-yellow solid $(1.10 \mathrm{~g}, 30 \%) .{ }^{1} \mathrm{H}-\mathrm{NMR}\left(400 \mathrm{MHz}, \mathrm{CDCl}_{3}\right): \delta 7.78(\mathrm{~d}$, $J=8.0 \mathrm{~Hz}, 2 \mathrm{H}, \mathrm{ArH}), 7.46(\mathrm{~d}, J=7.6 \mathrm{~Hz}, 2 \mathrm{H}, \mathrm{ArH}), 6.01\left(\mathrm{~s}, 2 \mathrm{H}\right.$, pyrrole-H), $2.56\left(\mathrm{~s}, 6 \mathrm{H}, \mathrm{CH}_{3}\right), 1.35(\mathrm{~s}, 6 \mathrm{H}$, $\mathrm{CH}_{3}$ ) ppm. HRMS (ESI): $m / z$ calcd for $\mathrm{C}_{20} \mathrm{H}_{19} \mathrm{BF}_{5} \mathrm{~N}_{2}[\mathrm{M}+\mathrm{H}]^{+}: 393.1556$, found 393.1550 [38].

\subsubsection{Synthesis of $\mathbf{1 b}$}

A similar procedure was employed to prepare compound $1 \mathbf{b}$ with a yield of $23 \%$ by replacing 4-(trifluoromethyl)benzaldehyde wth 3,5-bis(trifluoromethyl)benzaldehyde. ${ }^{1} \mathrm{H}-\mathrm{NMR}(400 \mathrm{MHz}$, $\left.\mathrm{CDCl}_{3}\right): \delta 8.03(\mathrm{~s}, 1 \mathrm{H}, \mathrm{ArH}), 7.84(\mathrm{~s}, 2 \mathrm{H}, \mathrm{ArH}), 6.03(\mathrm{~s}, 2 \mathrm{H}$, pyrrole- $\mathrm{H}), 2.57\left(\mathrm{~s}, 6 \mathrm{H}, \mathrm{CH}_{3}\right), 1.32(\mathrm{~s}, 6 \mathrm{H}$, $\mathrm{CH}_{3}$ ) ppm. HRMS (ESI): $m / z$ calcd for $\mathrm{C}_{21} \mathrm{H}_{18} \mathrm{BF}_{8} \mathrm{~N}_{2}[\mathrm{M}+\mathrm{H}]^{+}: 461.1430$, found 461.1425.

\subsubsection{Synthesis of $\mathbf{2 a}$}

The mixture of compound $1 \mathrm{a}(0.15 \mathrm{~g}, 0.39 \mathrm{mmol}), \mathrm{I}_{2}(0.39 \mathrm{~g}, 1.56 \mathrm{~mol})$ and $\mathrm{HIO}_{4}(0.23 \mathrm{~g}, 1.25 \mathrm{mmol})$ in absolute ethanol $(200 \mathrm{~mL})$ was stirred under an atmosphere of nitrogen for $6 \mathrm{~h}$ at $60^{\circ} \mathrm{C}$. The mixture was concentrated under reduced pressure after the reaction was completed, as monitored by thin-layer chromatography (TLC). Then the residue was purified by silica gel column chromatography using $\mathrm{CH}_{2} \mathrm{Cl}_{2}$ /petroleum ether $(1: 2, v / v)$ as the eluent to give $2 \mathrm{a}$ as a red solid $(0.31 \mathrm{~g}, 83 \%) .{ }^{1} \mathrm{H}-\mathrm{NMR}$ $\left(400 \mathrm{MHz}, \mathrm{CDCl}_{3}\right): \delta 7.82(\mathrm{~d}, J=7.6 \mathrm{~Hz}, 2 \mathrm{H}, \mathrm{ArH}), 7.44(\mathrm{~d}, J=8.0 \mathrm{~Hz}, 2 \mathrm{H}, \mathrm{ArH}), 2.66\left(\mathrm{~s}, 6 \mathrm{H}, \mathrm{CH}_{3}\right), 1.36$ (s, $6 \mathrm{H}, \mathrm{CH}_{3}$ ) ppm. HRMS (ESI): $m / z$ calcd for $\mathrm{C}_{20} \mathrm{H}_{16} \mathrm{BF}_{5} \mathrm{I}_{2} \mathrm{~N}_{2}[\mathrm{M}]^{+}: 643.9411$, found 643.9409.

\subsubsection{Synthesis of $\mathbf{2 b}$}

According to the above procedure, $\mathbf{1 b}(0.17 \mathrm{~g}, 0.37 \mathrm{~mol})$ was treated with $\mathrm{I}_{2}(0.24 \mathrm{~g}, 0.93 \mathrm{~mol})$ and $\mathrm{HIO}_{4}(0.13 \mathrm{~g}, 0.74 \mathrm{~mol})$ in absolute ethanol to afford $\mathbf{2 b}(0.20 \mathrm{~g}, 75 \%) .{ }^{1} \mathrm{H}-\mathrm{NMR}\left(400 \mathrm{MHz}, \mathrm{CDCl}_{3}\right): \delta$ $8.09(\mathrm{~s}, 1 \mathrm{H}, \mathrm{ArH}), 7.82(\mathrm{~s}, 2 \mathrm{H}, \mathrm{ArH}), 2.66\left(\mathrm{~s}, 6 \mathrm{H}, \mathrm{CH}_{3}\right), 1.34\left(\mathrm{~s}, 6 \mathrm{H}, \mathrm{CH}_{3}\right) \mathrm{ppm}$. HRMS (ESI): $m / z$ calcd for $\mathrm{C}_{21} \mathrm{H}_{15} \mathrm{BF}_{8} \mathrm{I}_{2} \mathrm{~N}_{2}[\mathrm{M}]^{+}:$: 711.9290, found 711.9303. 


\subsubsection{Synthesis of BDP3}

A mixture of compound 2a $(0.15 \mathrm{~g}, 0.24 \mathrm{mmol})$, 4-trifluoromethylbenzaldehyde $(0.41 \mathrm{~g}, 16 \mathrm{mmol})$, piperidine $(0.90 \mathrm{~mL})$, glacial acetic acid $(0.75 \mathrm{~mL})$ and a small amount of $\mathrm{Mg}\left(\mathrm{ClO}_{4}\right)_{2}$ in anhydrous toluene $(50 \mathrm{~mL})$ was refluxed for $2 \mathrm{~h}$. Water generated in the reaction was removed azeotropically with a Dean-Stark apparatus. The volatiles was removed under reduced pressure. The resulting residue was dissolved in dichloromethane and washed with water $(200 \mathrm{~mL} \times 2)$. The organic fraction was collected and purified by silica gel column chromatography using $\mathrm{CH}_{2} \mathrm{Cl}_{2} /$ petroleum ether $(2: 1, v / v)$ as the eluent. BDP3 was obtained as a green solid $(0.0052 \mathrm{~g}, 21 \%) .{ }^{1} \mathrm{H}-\mathrm{NMR}\left(400 \mathrm{MHz}, \mathrm{CDCl}_{3}\right)$ : $\delta$ $8.17(\mathrm{~d}, J=16.4 \mathrm{~Hz}, 2 \mathrm{H}, \mathrm{CH}=\mathrm{CH}), 7.86(\mathrm{~d}, J=8.0 \mathrm{~Hz}, 2 \mathrm{H}, \mathrm{ArH}), 7.75(\mathrm{~d}, J=8.4 \mathrm{~Hz}, 4 \mathrm{H}, \operatorname{ArH}), 7.74(\mathrm{~d}$, $J=16.0 \mathrm{~Hz}, 2 \mathrm{H}, \mathrm{CH}=\mathrm{CH}), 7.68(\mathrm{~d}, J=8.0 \mathrm{~Hz}, 4 \mathrm{H}, \mathrm{ArH}), 7.50(\mathrm{~d}, J=8.0 \mathrm{~Hz}, 2 \mathrm{H}, \mathrm{ArH}), 1.46\left(\mathrm{~s}, 6 \mathrm{H}, \mathrm{CH}_{3}\right)$ ppm. HRMS (ESI): $m / z$ calcd for $\mathrm{C}_{36} \mathrm{H}_{22} \mathrm{BF}_{11} \mathrm{I}_{2} \mathrm{~N}_{2}[\mathrm{M}]^{+}$: 955.9790 , found 955.9812 .

\subsubsection{Synthesis of BDP6}

According to the above procedure, $\mathbf{2 b}(0.10 \mathrm{~g}, 0.14 \mathrm{mmol})$ was treated with 3,5-bis(trifluoromethyl) benzaldehyde $(0.34 \mathrm{~g}, 20 \mathrm{mmol})$, piperidine $(0.90 \mathrm{~mL})$, and acetic acid $(0.75 \mathrm{~mL})$ to give BDP6 $(0.037 \mathrm{~g}$, $23 \%)$ as a green solid. ${ }^{1} \mathrm{H}-\mathrm{NMR}\left(400 \mathrm{MHz}, \mathrm{CDCl}_{3}\right): \delta 8.22(\mathrm{~d}, J=16.8 \mathrm{~Hz}, 2 \mathrm{H}, \mathrm{CH}=\mathrm{CH}), 8.15(\mathrm{~s}, 1 \mathrm{H}$, $\mathrm{ArH}), 8.03$ (s, 4H, ArH), 7.90 (s, 2H, ArH), 7.86 (s, 2H, ArH), 7.78 (d, J = 16.8 Hz, 2H, CH=CH), 1.45 (s, $6 \mathrm{H}, \mathrm{CH}_{3}$ ) ppm. HRMS (ESI): $\mathrm{m} / z$ calcd for $\mathrm{C}_{39} \mathrm{H}_{19} \mathrm{BF}_{20} \mathrm{I}_{2} \mathrm{~N}_{2}[\mathrm{M}]^{+}:$1159.9411, found 1159.9422 .

\subsection{Photo-Physical and Photo-Chemical Studies}

\subsubsection{Absorption and Fluorescence Studies}

UV-Vis and steady-state fluorescence spectra were obtained on a Beijing PuXi Tu-1901 spectrometer and a VARIAN Carye Elipse fluorescence spectrometer, respectively. The samples (BDP3 and BDP6) were dissolved in DMF in a quartz colorimetric utensil. The molar extinction coefficient was determined according to Lambert-Beer's law. Fluorescence emission spectra were recorded from $600 \mathrm{~nm}$ to $900 \mathrm{~nm}$ under the excitation at $610 \mathrm{~nm}$. Both the excitation and emission slits were set to $5 \mathrm{~nm}$. The fluorescence quantum yields were determined as:

$$
\Phi_{\mathrm{F}}=\left(\mathrm{F} / \mathrm{F}_{\mathrm{std}}\right)\left(\mathrm{A}_{\mathrm{std}} / \mathrm{A}\right) \Phi_{\mathrm{F}(\mathrm{std})}
$$

where $F$ and $F_{\text {std }}$ are the measured fluorescence area $\left(\lambda_{\mathrm{ex}}=610 \mathrm{~nm}\right.$, area under the emission peak) of the BODIPYs and standard; $A$ and $A_{\text {std }}$ are the absorbances at the excitation wavelength $(610 \mathrm{~nm})$ of the BODIPYs and standard. Here, the unsubstituted zinc(II) phthalocyanine (ZnPc) in DMF was used as the standard $\left[\Phi_{\mathrm{F}}=0.28\right]$. To minimize re-absorption of the radiation by the ground-state species, the emission spectra were obtained by controlling the absorbances of BODIPYs and ZnPc at $610 \mathrm{~nm}$ were within the range from 0.03 to 0.05 .

\subsubsection{Detection of Singlet Oxygen $\left({ }^{1} \mathrm{O}_{2}\right)$ Generation Efficiency}

Singlet oxygen quantum yields $\left(\Phi_{\Delta}\right)$ were indirectly measured according to our previous work [19]. In brief, 1,3-diphenylisobenzofuran (DPBF) was used as the scavenger and $\mathrm{ZnPc}$ was selected as the standard $\left(\Phi_{\Delta}=0.56\right.$ in DMF). A mixture of DPBF $(1 \mathrm{mM})$ (absorbance at $\left.415 \mathrm{~nm} \approx 1.6\right)$ and photosensitizer (absorbance of Q-band $\approx 1.0)$ in DMF $(3 \mathrm{~mL})$ was illuminated with laser $(670 \mathrm{~nm}$, $20 \mathrm{~mW}$ ). The decay of the DPBF absorption at $415 \mathrm{~nm}$ was monitored. The singlet oxygen quantum yields of photosensitizers were calculated as:

$$
\Phi_{\Delta}=\Phi_{\Delta \mathrm{std}}\left(\mathrm{k} / \mathrm{k}_{\mathrm{std}}\right)\left(\mathrm{I}_{\mathrm{std}} / \mathrm{I}\right)
$$


where $\Phi_{\Delta \text { std }}$ is the quantum yield of singlet oxygen formulation for $\mathrm{ZnPc} ; \mathrm{k}$ and $\mathrm{k}_{\text {std }}$ are respectively the DPBF photobleaching rates in the presence of BDP3 (or BDP6) and ZnPc; $I_{\text {std }}$ and I are the rates of light absorbed by BDP3 (or BDP6) and ZnPc.

\subsection{In Vitro Studies}

\subsubsection{Cell Culture and Conditions}

HepG2 human hepatocarcinoma and HeLa human cervical carcinoma cells were maintained in RPMI 1640 medium (Gibco) supplemented with Fetal Calf Serum $(10 \%, v / v)$, penicillin-streptomycin $(0.1 \%, v / v)$. These two cell lines were both cultured at $37{ }^{\circ} \mathrm{C}$ in a humidified atmosphere with $5 \%$ $\mathrm{CO}_{2}$. Approximately $7 \times 10^{4}$ (for HepG2 and HeLa) cells per well in these media were inoculated in 96-multiwell plates and incubated overnight at $37^{\circ} \mathrm{C}$ in a humidified $5 \% \mathrm{CO}_{2}$ atmosphere.

\subsubsection{Photocytotoxicity Studies}

Photosensitizers (BDP3 and BDP6) were first dissolved in dimethyl sulfoxide (DMSO) containing $5 \%$ Cremophor EL to give $1.0 \mathrm{mM}$ solutions, which were diluted to $10 \mu \mathrm{M}$ with the ultrapure water. The solutions were filtered with a $0.2 \mu \mathrm{m}$ filter, then diluted with the culture medium to appropriate concentrations $(0.001,0.005,0.01,0.1,0.5,1.0$, and $2.0 \mu \mathrm{M})$. The final contents of DMSO and Cremophor EL in the drug solutions were less than $0.2 \%$ and $0.01 \%$, respectively. The culture media containing $0.2 \%(v / v)$ DMSO and $0.01 \%(v / v)$ Cremophor EL as the controls are non-cytotoxicity in the presence and absence of light proved by our experiments (Figures S2 and S3). Approximately $7 \times 10^{3}$ cells (HepG2 and HeLa) per well in these media were inoculated in 96-multiwell plates and incubated overnight at $37^{\circ} \mathrm{C}$ in a humidified atmosphere with $5 \% \mathrm{CO}_{2}$. The cells, after being rinsed with PBS, were incubated with $100 \mu \mathrm{L}$ of these photosensitizer solutions at $37{ }^{\circ} \mathrm{C}$ under $5 \% \mathrm{CO}_{2}$. After $24 \mathrm{~h}$ incubation, the medium containing drugs was replaced by fresh medium and then the cells were illuminated at a light dosage of $1.5 \mathrm{~J} / \mathrm{cm}^{2}$ with a red LED lamp $(\lambda=660 \mathrm{~nm})$ for $20 \mathrm{~min}$.

Cell viability was determined by the colorimetric MTT assay [39]. After illumination, the cells were incubated for another $24 \mathrm{~h}$ and then a MTT solution in PBS $(10 \mu \mathrm{L}, 4 \mathrm{mg} / \mathrm{mL})$ was added to each well. The plates were incubated again for $4 \mathrm{~h}$. The medium was removed carefully and DMSO $(100 \mu \mathrm{L})$ was added to each well. The absorbance of the solution at $570 \mathrm{~nm}$ in each well was taken by a microplate reader. The average absorbance of the blank wells, which did not contain the cells, was subtracted from the readings of the other wells. The cell viability was then determined by the following equation: \% viability $=\left[\sum\left(A_{i} / A_{\text {control }} \times 100\right)\right] / n$, where $A_{i}$ is the absorbance of the ith data $(i=1,2, \ldots, n), A_{\text {control }}$ is the average absorbance of the control wells in which the BODIPY was absent, and $\mathrm{n}(=6)$ is the number of the data points. Six replicates were used for each concentration in each experiment and each experiment was repeated three times. The procedures for investigation of dark-cytotoxicity were almost the same except that there was no irradiation. The dose-dependent survival curves were prepared with GraphPad Prism 5.0 Software (GraphPad Software Inc., La Jalla, CA, USA) and $\mathrm{IC}_{50}$ was calculated.

\subsubsection{Measurements of Intracellular ROS}

ROS was measured on the basis of the intracellular peroxide-dependent oxidation reaction of DCFH-DA [37] to form the fluorescent compound DCF. HepG2 cells were seeded onto a 96-well plate at a density of $5 \times 10^{3}$ cells per well and cultured overnight. Then fresh medium containing drugs $(0.5 \mu \mathrm{M}, 0.01 \%$ Cremophor EL) was added and the cells were incubated for $24 \mathrm{~h}$ in dark. After washing three times with PBS, $40 \mu \mathrm{L}$ of DCFH-DA $(10 \mu \mathrm{M})$ was added and the cells were incubated for another $30 \mathrm{~min}$. The medium was removed and the cells were washed three times with PBS, followed by illumination at a light dosage of $1.5 \mathrm{~J} / \mathrm{cm}^{2}$ with a red LED lamp $(\lambda=660 \mathrm{~nm})$ for $20 \mathrm{~min}$. After illumination, the medium was gently removed and then a solution of sodium dodecyl sulfate (SDS, Sigma; $1 \%$ by weight, $120 \mu \mathrm{L}$ ) was then added to each well. The plate was agitated for $20 \mathrm{~min}$ 
on a constant temperature shaker. Then the DCF fluorescence was measured by a Bio-Tek microplate reader (Corning Incorporated., New York, NY, USA) (excitation/emission: 488/525 nm). The culture medium containing $50 \mu \mathrm{g} / \mathrm{mL}$ Rosup (a compound mixture, provided by the assay kit) was used as a positive control. The culture medium containing no agent was used as a negative control. Both of them were subjected to irradiation with a light dosage of $1.5 \mathrm{~J} / \mathrm{cm}^{2}$. Six replicates were used for each experiment and each experiment was repeated three times.

\subsubsection{Subcellular Localization Studies}

Approximately $1 \times 10^{4}$ HepG2 or HeLa cells in logarithmic growth phase were added on a cell culture dish and incubated overnight. Then the medium was replaced by fresh medium containing drugs $(2 \mu \mathrm{M})$ and the cells were incubated for $24 \mathrm{~h}$ again. After incubation, the cells were rinsed with PBS three times and incubated with DAPI (Beyutime Institute of Biotechnology Co., Ltd., Haimen, China, $2 \mu \mathrm{M}$ in culture medium, incubated for $10 \mathrm{~min}$ ), Mito-Tracker Green (Beyutime Institute of Biotechnology Co., Ltd., Haimen, China, $2 \mu \mathrm{M}$ in culture medium, incubated for $30 \mathrm{~min}$ ), or Lyso-Tracker DND-26 (Xiamen Bioluminor Bio-Technology Co., Ltd., Xiamen, China, $2 \mu \mathrm{M}$ in culture medium, incubated for $1 \mathrm{~h}$ ). Then the cells were rinsed with PBS three times again and examined with an Olympus FV1000 Confocal Laser Scanning Microscope (Olympus Instrument Co., Ltd., Shinjuku-ku, Tokyo, Japan). Specimens were excited by laser at $405 \mathrm{~nm}$ (DAPI), $488 \mathrm{~nm}$ (Mito-Tracker Green), $488 \mathrm{~nm}$ (Lyso-Tracker DNd-26) or $633 \mathrm{~nm}$ (BDP3 or BDP6), and the fluorescence emissions (the first one (blue, 425-475 $\mathrm{nm}$ ), the second one (green, 510-570 nm), the third one (green, 510-570 nm), and the last one (red, 650-750 nm)) were collected.

\section{Conclusions}

We have successfully synthesized two trifluoromethyl BODIPY derivatives (BDP3 and BDP6) and investigated their photo-physical, photo-chemical, and photo-biological properties. The results show that the two BODIPYs, formulated with Cremophor EL in the RPMI 1640 culture medium, are slightly aggregated and mainly exist in the monomeric form in the biological medium, leading to their high cellular ROS generation efficiency; moreover, the two photosensitizers are specially localized in the mitochondria and lysosomes exhibiting high photocytotoxicity towards HepG2 and HeLa cancer cells with the $\mathrm{IC}_{50}$ values of $0.42-0.49 \mu \mathrm{M}$. All these results indicate that the trifluoromethyl BODIPYs are promising antitumor agents for photodynamic therapy.

Supplementary Materials: Supplementary materials are available online at www.mdpi.com/1420-3049/23/2/ 458/s1.

Acknowledgments: We gratefully acknowledge financial supports from the National Natural Science Foundation of China (project No. 21471033), the Key Project of Science and Technology Development of Fujian Province (project No. 2015Y0086), the Independent Research Project of State Key Laboratory of Photocatalysis on Energy and Environment (project No. 2014C04) and the Investment from Testing Center of Fuzhou University (project Nos. 2018T010 and 2017T011).

Author Contributions: J.-Y.L., P.-Z.Z., J.-L.M. and X.J. conceived and designed the experiments; P.-Z.Z. and J.-L.M. performed the experiments and analyzed the data; J.-Y.L. and P.-Z.Z. wrote the paper; J.-Y.L. supervised the process.

Conflicts of Interest: The authors declare no conflict of interest.

\section{References}

1. LIPSON, R.L.; BALDES, E.J. The photodynamic properties of a particular hematoporphyrin derivative. Arch. Dermatol. 1960, 82, 508-516. [CrossRef] [PubMed]

2. Takahashi, H.; Nakajima, S.; Sakata, I.; Ishida-Yamamoto, A.; Iizuka, H. Photodynamic therapy using a novel photosensitizer, ATX-S10(Na): Comparative effect with 5-aminolevulinic acid on squamous cell carcinoma cell line, SCC15, ultraviolet B-induced skin tumor, and phorbol ester-induced hyperproliferative skin. Arch. Dermatol. Res. 2005, 296, 496-502. [CrossRef] [PubMed] 
3. Juzeniene, A.; Nielsen, K.P.; Moan, J. Biophysical Aspects of Photodynamic Therapy. J. Environ. Pathol. Toxicol. Oncol. 2006, 25, 7-28. [CrossRef] [PubMed]

4. Agostinis, P.; Berg, K.; Cengel, K.A.; Foster, T.H.; Girotti, A.W.; Gollnick, S.O.; Hahn, S.M.; Hamblin, M.R.; Juzeniene, A.; Kessel, D.; et al. Photodynamic therapy of cancer: An update. CA Cancer J. Clin. 2011, 61, 250-281. [CrossRef] [PubMed]

5. Allison, R.R.; Moghissi, K. Photodynamic Therapy (PDT): PDT Mechanisms. Clin. Endosc. 2013, 46, 24-29. [CrossRef] [PubMed]

6. Robertson, C.A.; Evans, D.H.; Abrahamse, H. Photodynamic therapy (PDT): A short review on cellular mechanisms and cancer research applications for PDT. J. Photochem. Photobiol. B 2009, 96, 1-8. [CrossRef] [PubMed]

7. Wang, J.; Yi, J. Cancer cell killing via ROS: To increase or decrease, that is the question. Cancer Biol. Ther. 2008, 7, 1875-1884. [CrossRef] [PubMed]

8. Lai, Y.C.; Su, S.Y.; Chang, C.C. Special reactive oxygen species generation by a highly photostable BODIPY-based photosensitizer for selective photodynamic therapy. ACS Appl. Mater. Interfaces 2013, 5, 12935-12943. [CrossRef] [PubMed]

9. Yang, Y.; Guo, Q.; Chen, H.; Zhou, Z.; Guo, Z.; Shen, Z. Thienopyrrole-expanded BODIPY as a potential NIR photosensitizer for photodynamic therapy. Chem. Commun. 2013, 49, 3940-3942. [CrossRef] [PubMed]

10. Pucelik, B.; Gurol, I.; Ahsen, V.; Dumoulin, F.; Dabrowski, J.M. Fluorination of phthalocyanine substituents: Improved photoproperties and enhanced photodynamic efficacy after optimal micellar formulations. Eur. J. Med. Chem. 2016, 124, 284-298. [CrossRef] [PubMed]

11. Pereira, N.A.; Laranjo, M.; Pineiro, M.; Serra, A.C.; Santos, K.; Teixo, R.; Abrantes, A.M.; Goncalves, A.C.; Sarmento Ribeiro, A.B.; Casalta-Lopes, J.; et al. Novel 4,5,6,7-tetrahydropyrazolo[1,5-a]pyridine fused chlorins as very active photodynamic agents for melanoma cells. Eur. J. Med. Chem. 2015, 103, 374-380. [CrossRef] [PubMed]

12. Eggenspiller, A.; Takai, A.; El-Khouly, M.E.; Ohkubo, K.; Gros, C.P.; Bernhard, C.; Goze, C.; Denat, F.; Barbe, J.M.; Fukuzumi, S. Synthesis and photodynamics of fluorescent blue BODIPY-porphyrin tweezers linked by triazole rings. J. Phys. Chem. A 2012, 116, 3889-3898. [CrossRef] [PubMed]

13. He, H.; Lo, P.C.; Yeung, S.L.; Fong, W.P.; Ng, D.K. Preparation of unsymmetrical distyryl BODIPY derivatives and effects of the styryl substituents on their in vitro photodynamic properties. Chem. Commun. 2011, 47, 4748-4750. [CrossRef] [PubMed]

14. Lang, K.; Mosinger, J.; Wagnerová, D.M. Photophysical properties of porphyrinoid sensitizers non-covalently bound to host molecules; models for photodynamic therapy. Coord. Chem. Rev. 2004, 248, 321-350. [CrossRef]

15. Cho, Y.; Choi, Y. Graphene oxide-photosensitizer conjugate as a redox-responsive theranostic agent. Chem. Commun. 2012, 48, 9912-9914. [CrossRef] [PubMed]

16. Detty, M.R.; Gibson, S.L.; Wagner, S.J. Current clinical and preclinical photosensitizers for use in photodynamic therapy. J. Med. Chem. 2004, 47, 3897-3915. [CrossRef] [PubMed]

17. Scalise, I.; Durantini, E.N. Synthesis, properties, and photodynamic inactivation of Escherichia coli using a cationic and a noncharged Zn(II) pyridyloxyphthalocyanine derivatives. Bioorg. Med. Chem. 2005, 13, 3037-3045. [CrossRef] [PubMed]

18. Liu, J.Y.; Wang, C.; Zhu, C.H.; Zhang, Z.H.; Xue, J.P. Preparation and In Vitro Photodynamic Activity of Glucosylated Zinc(II) Phthalocyanines as Underlying Targeting Photosensitizers. Molecules 2017, 22, 845-857. [CrossRef] [PubMed]

19. Liu, J.Y.; Lo, P.C.; Jiang, X.J.; Fong, W.P.; Ng, D.K. Synthesis and in vitro photodynamic activities of di-alpha-substituted zinc(II) phthalocyanine derivatives. Dalton T. 2009, 4129-4135. [CrossRef] [PubMed]

20. Kamkaew, A.; Lim, S.H.; Lee, H.B.; Kiew, L.V.; Chung, L.Y.; Burgess, K. BODIPY dyes in photodynamic therapy. Chem. Soc. Rev. 2013, 42, 77-88. [CrossRef] [PubMed]

21. Loudet, A.; Burgess, K. BODIPY ${ }^{\circledR}$ Dyes and Their Derivatives: Syntheses and Spectroscopic Properties. Chem. Rev. 2007, 107, 4891-4932. [CrossRef] [PubMed]

22. Yogo, T.; Urano, Y.; Ishitsuka, Y.; Maniwa, F.; Nagano, T. Highly efficient and photostable photosensitizer based on BODIPY chromophore. J. Am. Chem. Soc. 2005, 127, 12162-12163. [CrossRef] [PubMed]

23. Erbas, S.; Gorgulu, A.; Kocakusakogullari, M.; Akkaya, E.U. Non-covalent functionalized SWNTs as delivery agents for novel Bodipy-based potential PDT sensitizers. Chem. Commun. 2009, 33, 4956-4958. [CrossRef] [PubMed] 
24. Zhang, X.; Xiao, Y.; Qian, X. Highly efficient energy transfer in the light harvesting system composed of three kinds of boron-dipyrromethene derivatives. Org. Lett. 2008, 10, 29-32. [CrossRef] [PubMed]

25. Zhou, J.; Gai, L.; Zhou, Z.; Mack, J.; Xu, K.; Zhao, J.; Qiu, H.; Chan, K.S.; Shen, Z. Highly efficient near IR photosensitizers based-on Ir-C bonded porphyrin-aza-BODIPY conjugates. RSC Adv. 2016, 6, 72115-72120. [CrossRef]

26. Guo, Z.; Zou, Y.; He, H.; Rao, J.; Ji, S.; Cui, X.; Ke, H.; Deng, Y.; Yang, H.; Chen, C.; Zhao, Y.; Chen, H. Bifunctional Platinated Nanoparticles for Photoinduced Tumor Ablation. Adv. Mater. 2016, 28, 10155-10164. [CrossRef] [PubMed]

27. Yao, L.; Xiao, S.; Dan, F. Boron-Fluorine Photosensitizers for Photodynamic Therapy. J. Chem. 2013, 2013, 1-10. [CrossRef]

28. Banfi, S.; Caruso, E.; Zaza, S.; Mancini, M.; Gariboldi, M.B.; Monti, E. Synthesis and photodynamic activity of a panel of BODIPY dyes. J. Photochem. Photobiol. B 2012, 114, 52-60. [CrossRef] [PubMed]

29. Kucukoz, B.; Sevinc, G.; Yildiz, E.; Karatay, A.; Zhong, F.; Yilmaz, H.; Tutel, Y.; Hayvali, M.; Zhao, J.; Yaglioglu, H.G. Enhancement of two photon absorption properties and intersystem crossing by charge transfer in pentaaryl boron-dipyrromethene (BODIPY) derivatives. Phys. Chem. Chem. Phys. 2016, 18, 13546-13553. [CrossRef] [PubMed]

30. Ismail, F.M. Important fluorinated drugs in experimental and clinical use. J. Fluorine Chem. 2002, 118, 27-33. [CrossRef]

31. Isanbor, C.; O'Hagan, D. Fluorine in medicinal chemistry: A review of anti-cancer agents. J. Fluorine Chem. 2006, 127, 303-319. [CrossRef]

32. Kirk, K.L. Fluorine in medicinal chemistry: Recent therapeutic applications of fluorinated small molecules. J. Fluorine Chem. 2006, 127, 1013-1029. [CrossRef]

33. Lazzeri, D.; Rovera, M.; Pascual, L.; Durantini, E.N. Photodynamic Studies and Photoinactivation of Escherichia coli Using mesoeri, D.; Rov Cationic Porphyrin Derivatives with Asymmetric Charge Distribution. Photochem. Photobiol. 2004, 80, 286-293.

34. Watley, R.L.; Awuah, S.G.; Bio, M.; Cantu, R.; Gobeze, H.B.; Nesterov, V.N.; Das, S.K.; D’Souza, F.; You, Y. Dual Functioning Thieno hotoproperties and enhanced photodynamic efficacy after optimal micTherapy: Singlet Oxygen Generation without Heavy Halogen Atom Assistance. Chem. Asian J. 2015, 10, 1335-1343. [CrossRef] [PubMed]

35. Shao, J.; Dai, Y.; Zhao, W.; Xie, J.; Xue, J.; Ye, J.; Jia, L. Intracellular distribution and mechanisms of actions of photosensitizer Zinc(II)-phthalocyanine solubilized in Cremophor EL against human hepatocellular carcinoma HepG2 cells. Cancer Lett. 2013, 330, 49-56. [CrossRef] [PubMed]

36. Maillard, P.; Loock, B.; Grierson, D.S.; Laville, I.; Blais, J.; Doz, F.; Desjardins, L.; Carrez, D.; Guerquin-Kern, J.-L.; Croisy, A. In vitro phototoxicity of glycoconjugated porphyrins and chlorins in colorectal adenocarcinoma (HT29) and retinoblastoma (Y79) cell lines. Photodiagn. Photodyn. Ther. 2007, 4, 261-268. [CrossRef] [PubMed]

37. Ding, R.; Zhang, C.; Zhu, X.; Cheng, H.; Zhu, F.; Xu, Y.; Liu, Y.; Wen, L.; Cao, J. ROS-AKT-mTOR axis mediates autophagy of human umbilical vein endothelial cells induced by cooking oil fumes-derived fine particulate matters in vitro. Free Radical Biol. Med. 2017, 113, 452-460. [CrossRef] [PubMed]

38. Wang, M.; Zhang, Y.; Wang, T.; Wang, C.; Xue, D.; Xiao, J. Story of an Age-Old Reagent: An Electrophilic Chlorination of Arenes and Heterocycles by 1-Chloro-1, 2-benziodoxol-3-one. Org. Lett. 2016, 18, 1976-1979. [CrossRef] [PubMed]

39. Tada, H.; Shiho, O.; Kuroshima, K.; Koyama, M.; Tsukamoto, K. An improved colorimetric assay for interleukin 2. J. Immunol. Methods 1986, 93, 157-165. [CrossRef]

Sample Availability: Not available. 